\title{
Determination of Cooking Degree of Boiled and Steam Cooked Potatoes (Solanum tuberosum L.) from a Physico-Chemical and Sensorial Perspective
}

\author{
Klara Sjölin*, Marilyn Rayner, Ingegerd Sjöholm and Jeanette Purhagen \\ Department of Food Technology, Engineering and Nutrition, Faculty of Engineering, Chemical Centre, Lund \\ University, 221 00, Lund, Sweden \\ Email: klara.sjolin@food.lth.se
}

\begin{abstract}
Potatoes served in large-scale food service systems are often of poor quality. The current recommendation is to cook the potatoes until the core has reached a temperature of $96^{\circ} \mathrm{C}$, but this recommendation is questionable. In this study, three potato varieties have been cooked by using conventional boiling (CB) to temperatures of $94^{\circ} \mathrm{C}$ and $96^{\circ} \mathrm{C}$ and steam cooking (SC) to temperatures of $92^{\circ} \mathrm{C}, 94^{\circ} \mathrm{C}$ and $96^{\circ} \mathrm{C}$. The samples were thereafter analyzed by both texture and sensorial analyses. The results were evaluated with Partial Linear Squares Regression (PLSR). The perceived Softness and Cooking Degree from the sensorial analysis agreed with the hardness measured by the texture analyzer. The general impression of the samples showed that an undercooked tuber was preferable to an overcooked tuber, and that a cooking temperature of $96^{\circ} \mathrm{C}$ mostly resulted in overcooked tubers. The general impression depended on several parameters. Therefore, no optimal cooking temperature could be established.
\end{abstract}

Keywords: Potatoes (Solanum tuberosum L.), boiling, steam cooking, sensorial analysis, texture analysis, multivariate analysis, cooking degree

\section{Introduction}

Potato is a staple food in the Swedish diet, and the average consumption in 2015 was $56 \mathrm{~kg}$ of potatoes per person. During the past half century, potato consumption in Sweden has decreased by $35.7 \%$. However, in the last couple of years the trend has started to change, and there has even been a slight increase [1]. Potatoes are often served in school canteens and hospitals, but unfortunately, the quality is often too poor, resulting in a low intake of potatoes and increased food waste. Several factors are affecting the quality of the potatoes, such as the tuber properties, the pre-peeling process and insufficient control during the cooking process $[2,3]$.

Potatoes were traditionally cooked by conventional boiling (CB) in water, but nowadays steam cooking (SC) has become more popular, especially in large-scale food service systems. The fundamental difference between the two cooking processes is that in $\mathrm{CB}$ liquid water is used as the heat transfer medium, while saturated steam is used during the SC process. An advantage with $\mathrm{SC}$ compared to $\mathrm{CB}$ is that it maintains the nutritional values of the product during the cooking process to a higher degree [4]. A disadvantage though is that the cooking process of the entire batch is affected if the door is opened during the cooking process. During CB, the cooking degree can easily be checked without affecting the cooking process of the rest of the batch. How to determine when a potato is ready differs between the different large-scale food service systems, but the general recommendation in Sweden is that the potatoes are considered ready when the core has reached $96^{\circ} \mathrm{C}$. However, this recommendation is based on a small, unpublished study of only one variety, which was cooked by $\mathrm{CB}$ to different core temperatures, and the recommended temperature, $96^{\circ} \mathrm{C}$, was based on an interpolation between the measured temperatures [5].

During the cooking procedure, the tuber undergoes both physical and structural changes due to heat and enzymatic activity (Fig. 1), which determines the final texture and quality of cooked potatoes. The main physical changes during the cooking are swelling and gelatinization of starch. Potato starch gelatinizes in the range of $57-71^{\circ} \mathrm{C}[6,7]$. The wide temperature range reflects the broad size range of starch granules and the method used for analysis [7]. Due to the gelatinization of the starch, the cell 
pressure increases, thus increasing the pressure on the cell walls. The increased pressure may lead to a release of pectin from the cell walls to the intercellular matrix $[7,8]$. If the potato is preheated at $60^{\circ} \mathrm{C}$, the amount of pectin in the cell wall matrix seems to increase [9]. The pectin can then react with pectin methylesterase (PME), forming firm complexes [9]. This phenomenon has been studied during the heating of potatoes to different temperatures. At $70^{\circ} \mathrm{C}$, differences in cell wall structure could be noted. This change did not occur at lower temperatures independent of the holding time [10].

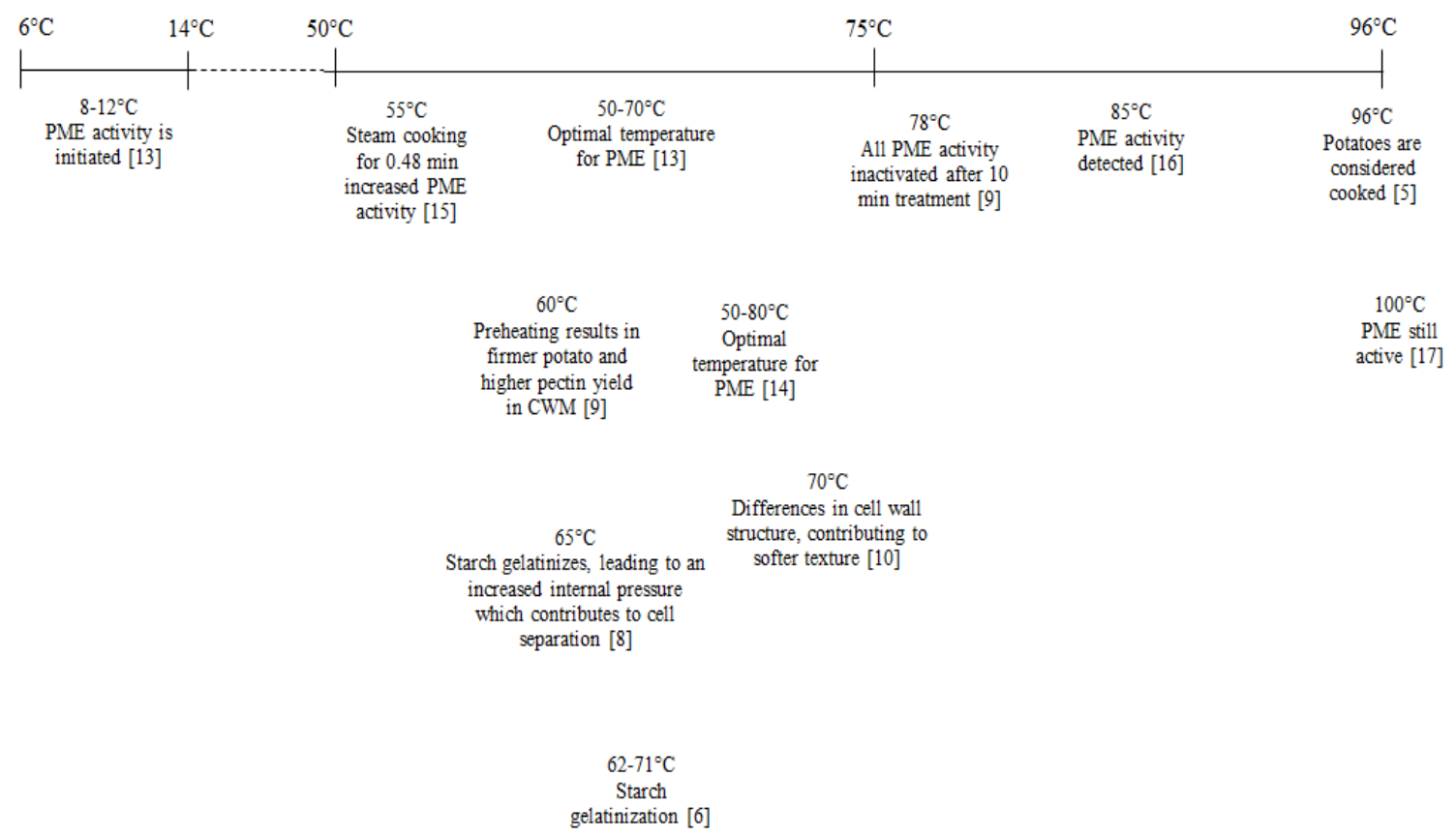

Figure 1. Summary of physical and enzymatic changes during cooking of potatoes.

Various enzymes are activated during the cooking process. PME is the enzyme that has the greatest impact on the final textural quality of the product. PME removes methyl groups from the pectin chains and enables the pectin chains to cross-link. The cross-linked pectin is very stable and the potato can be perceived as hard when consumed [9, 11]. PME occurs in different types, with different optimal and deactivation temperatures [12]. The optimal temperature for $\mathrm{PME}$ is in the range $50-80^{\circ} \mathrm{C}[9,11,13-15]$, but studies have shown PME activity already at $8-12^{\circ} \mathrm{C}[14]$ and at higher temperatures as well [16, 17].

Table 1. Composition of fresh weight of the potato (\%) [18].

\begin{tabular}{ll}
\hline Component & Content range (\%) \\
\hline Dry matter & $13.1-36.8$ \\
Total carbohydrate & $13.3-30.53$ \\
Starch & $8.5-29.4$ \\
Protein & $0.7-4.6$ \\
Fat & $0.02-0.2$ \\
Ash & $0.44-1.9$ \\
\hline
\end{tabular}

Potatoes are generally categorized as mealy or waxy, and the composition of raw potatoes (based on fresh weight basis) can be seen in Table 1. The main component is starch, and in naturally occurring varieties, it varies between 8.5 and $29.4 \%$. The starch content is proportional to the dry matter content of the potato [18]. The mealy potato varieties usually have a higher starch content [19] and also larger cells and starch granules compared to the waxy varieties [20], but there is no difference in the amylose/amylopectin ratio based on the type [21]. Based on the characteristics of the variety, the 
changes during cooking differ. During cooking, the cells of mealy varieties tend to separate, while the cell walls of waxy varieties tend to break [22]. Mealy varieties are also perceived as being drier and more crumbly after cooking as compared to waxy varieties [19].

The aim of the study was to investigate when a potato is ready to consume, and how variety, cooking method, core temperature and cooking time affect the cooking degree. The properties were analyzed by sensorial and texture analysis.

\section{Materials and Methods}

\subsection{Sample Preparation}

An overview of the experimental setup can be seen in Fig. 2.

Three varieties of Solanum tuberosum L. have been evaluated: Asterix, Bintje and Salome. Asterix and Salome are considered waxy while Bintje is considered mealy. The Salome was grown in Denmark and the Asterix and Bintje in the southern part of Sweden during 2016. The analyses were performed in November 2016. The shortest cross-section of the tubers was $46 \pm 4 \mathrm{~mm}$. Asterix and Bintje were more oval-shaped compared to the more spherical Salome.

The samples were cooked either by CB until the average core temperature of five tubers were $94^{\circ} \mathrm{C}$ or $96^{\circ} \mathrm{C}$ respectively, or by $\mathrm{SC}$ until the average core temperature of five tubers were $92^{\circ} \mathrm{C}, 94^{\circ} \mathrm{C}$ or $96^{\circ} \mathrm{C}$ respectively. The temperature was monitored for five tubers with thermocouples Type K (diameter of $0.5 \mathrm{~mm}$ ) connected to Thermocouple Data Logger USB TC-08, Pico Technology LTD., UK. The thermocouples were placed in the core of the tubers by connecting a thread and pulling them through the tuber until the tip of the thermocouple was located in the center.

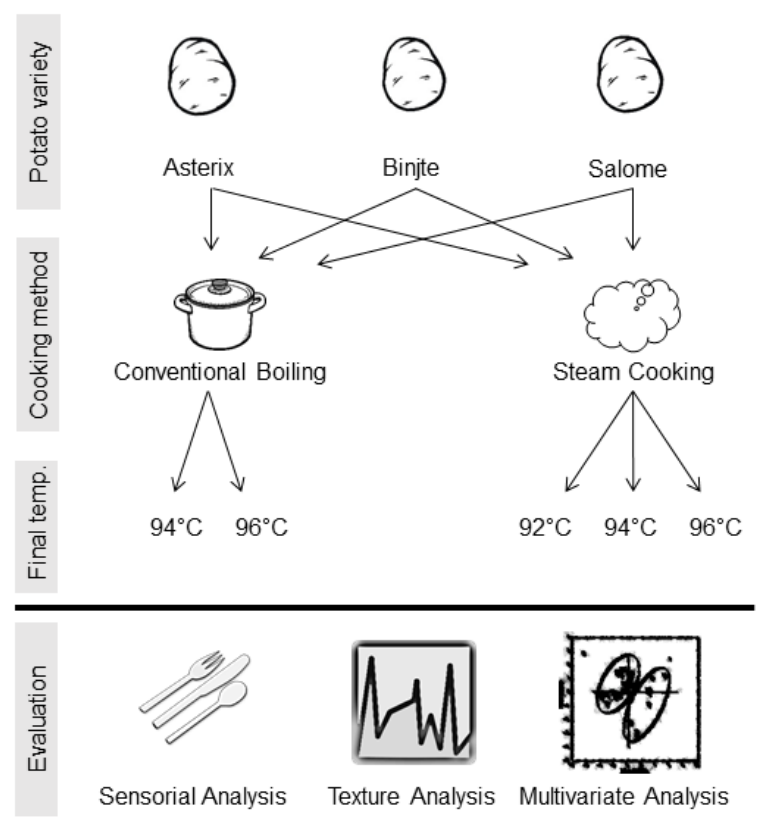

Figure 2. Overview of experimental setup.

\subsection{Sensorial Analysis}

Sensorial analysis was performed by a semi-trained panel $(n=18)$ consisting of a student group (age 2250 years, average 31 years) with previous experience of the product, both as consumers $(75 \%)$ and personnel in large scale food service systems (50\%). A practice session was organized where it was concluded how to judge different samples according to the selected parameters. A hedonic scale ranging from 1 to 10 was used for the evaluation. The evaluated parameters (translated from Swedish) were 
Cooking Degree (SensCD) (raw to overcooked), Softness (SensS) (very hard to very soft) and General Impression (SensGI) (liking a lot to disliking a lot). During the training it was emphasized that SensCD and SensS should be judged objectively and SensGI subjectively. The data has been normalized and standardized.

\subsection{Texture Analysis}

Texture analysis was performed using a TVT-300XP (Perten Instruments AB) equipped with a $7 \mathrm{~kg}$ load cell. The tubers were cut in half and placed on a stand with the flat side facing upwards. A $3 \mathrm{~mm}$ cylindrical probe was used to penetrate the tuber to a depth of $12 \mathrm{~mm}$ with a rate of $1 \mathrm{~mm} / \mathrm{s}$. The required force was monitored.

The weight of each sample was recorded by the texture analyzer. Peak Force (PF) corresponds to the greatest force required to penetrate the sample. Peak Time (PT) corresponds to the time that PF occurs.

\subsection{Dry Matter}

The Dry Matter (DM) was determined by drying slices representing the entire tuber of each variety at $102^{\circ} \mathrm{C}$ for $48 \mathrm{~h}$. The weight of each slice was in the range of $3-6 \mathrm{~g}$. The analysis was performed in triplicate.

\subsection{Statistical Analysis}

For the texture analysis, 10 tubers were analyzed with two tests per tuber for each variety and treatment. Data where PF occurs at $\mathrm{PT}<6 \mathrm{~s}$ is considered true and is included in the results. Outliers were identified by Grubb's test $(\mathrm{p}>0.05)$. One outlier was detected for SC Salome $96^{\circ} \mathrm{C}$ and one for $\mathrm{CB}$, Asterix, $96^{\circ} \mathrm{C}$. For CB, Asterix, $96^{\circ} \mathrm{C}$ PT was also identified as an outlier.

All graphs are presented with mean values and error bars showing a $95 \%$ confidence interval.

The multivariate analysis was performed in Unscrambler X 10.2 (CAMO Software), and the average of five tubers were used in the model for each predictor setup. Partial Least Squares Regression (PLSR) was performed. PLSR takes into consideration how each predictor affects the variables. PLSR finds the maximum correlation between the predictors (design parameters) and the variables (result outcome), and creates factors explaining the correlations, with Factor 1 having the highest degree of explanation. The results are presented in graphs with different factors represented on different axes. The further from origin a property appears, the better it is explained by the model. Properties that are grouped together are positively correlated while properties on opposite sides are negatively correlated. If the properties are located orthogonally, there is no strong dependence.

\section{Results and Discussion}

\subsection{Multivariate Analysis}

Accumulated explanation degree for the first four factors for predictors and variables respectively can be seen in Table 2.

Table 2. Accumulated explanation degree for the four first factors in the PLSR.

\begin{tabular}{lll}
\hline & Predictors & Variables \\
\hline Factor 1 & $26 \%$ & $22 \%$ \\
Factor 2 & $49 \%$ & $43 \%$ \\
Factor 3 & $67 \%$ & $63 \%$ \\
Factor 4 & $83 \%$ & $70 \%$ \\
\hline
\end{tabular}

Fig 3 and Fig 4 show PLSR with Factor 1 and Factor 2, and Factor 1 and 3, respectively. Factor 1 mainly explains variations caused by temperature. Cooking to $92^{\circ} \mathrm{C}$ is negatively correlated with the 
sensorial Cooking Degree and Softness, but positively correlated with the sensorial attribute General Impression. $96^{\circ} \mathrm{C}$ correlates positively with the final temperature and negatively with $\mathrm{PF}$, meaning that a potato that is boiled to a higher temperature becomes softer.

The sensorial attributes Softness and Cooking Degree seem to be closely related to the cooking method. The model suggests that CB results in softer tuber than SC. Softness and Cooking Degree are positively correlated, probably since those characteristics are closely connected.

Factor 2 distinguishes between the varieties, where the mealy variety Bintje seems to need a longer cooking time. This contradicts previous studies where mealy varieties have tended to have a shorter cooking time. However, mealy varieties also tend to have higher DM, which can explain the location of Bintje in the model, since it is also positively correlated to DM [23, 24]. The cooking times in this study do not show any significant correlation to the core temperature (data not shown).

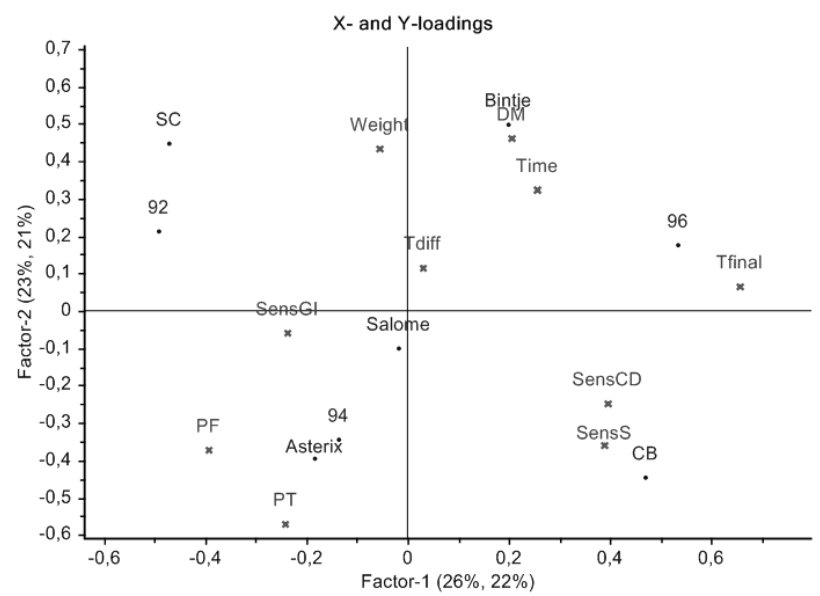

Figure 3. PLSR (Factor 1 and Factor 2) showing relations between the predictors (marked with • ) and variables (marked with $\mathrm{x}$ ) for different attributes.

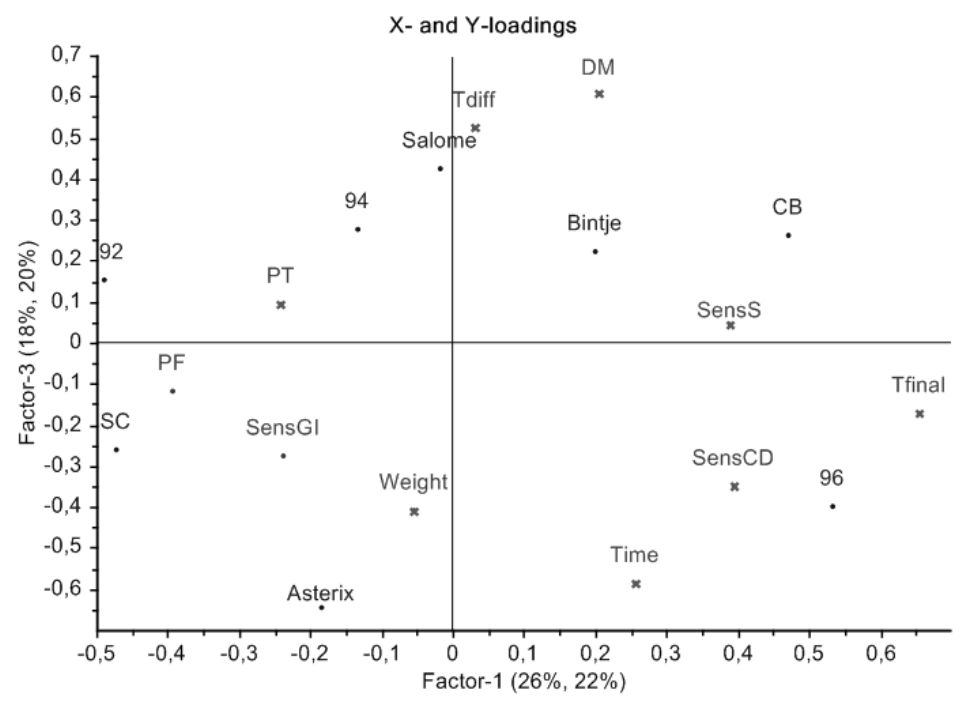

Figure 4. PLSR (Factor 1 and Factor 3) showing relations between the predictors (marked with • ) and variables (marked with $\mathrm{x}$ ) different components.

In Fig. 4, PLSR with Factor 1 and Factor 3 can be seen. Factor 3 shows that Tdiff has some impact on the model based on variety and weight of the sample. This relation in combination with the weight 
has been investigated further in paragraph 3.2. A positive relation between PF and Softness also becomes more obvious compared to Factor 2.

\subsection{Cooking Process}

Fig. 5 shows how Tdiff depends on the weight of the tuber for each variety, and the trend lines show the relation for each variety.

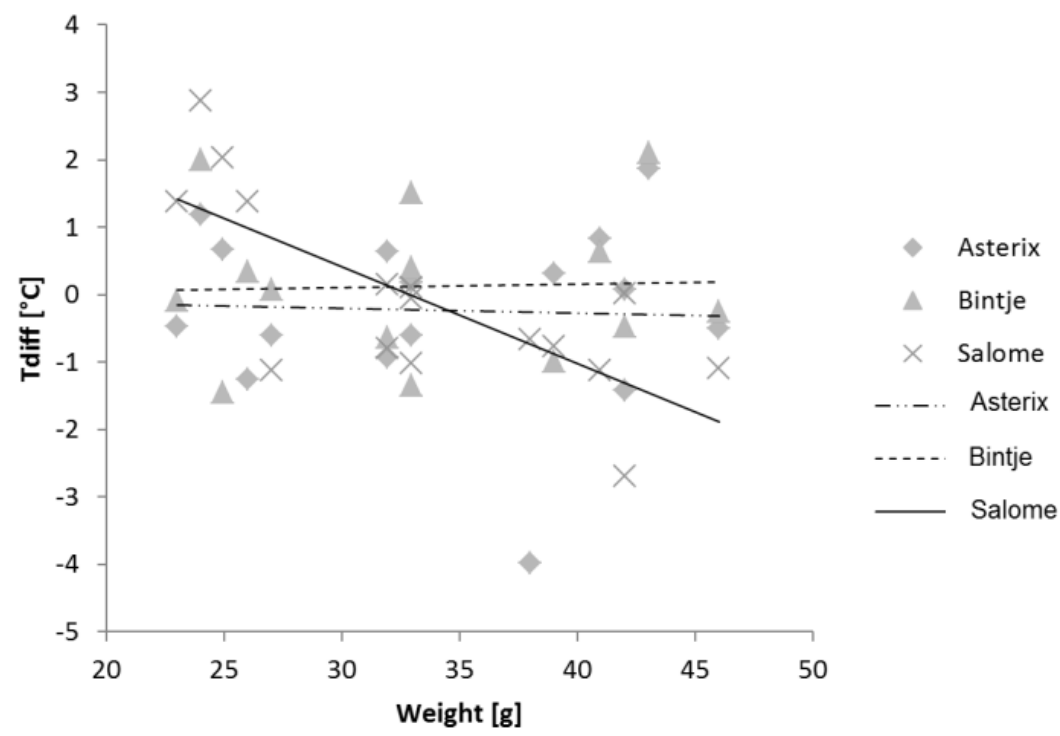

Figure 5. The deviation in final temperature (Tdiff) compared to the set temperature dependent on the weight of each sample.

Salome shows the strongest dependency between Tdiff and weight, but the relation is too weak for significance $\left(R_{2}=0.54\right)$. The most likely explanation of the stronger correlation for Salome was the difference in shapes of the raw tubers. Salome was more spherical while Asterix and Bintje were more oval. If the weight increased for Salome, the shortest diameter also increased. A weight increase for any of the other varieties might be caused by a more oval tuber. This also shows that it was the shortest diameter that mainly affected the heat transfer during the cooking of potatoes.

\subsection{Dry Matter}

The mean dry matter \pm standard deviation for Asterix, Bintje and Salome were 23.3 $\pm 1.2 \%, 22.2 \pm 1.0 \%$ and $18.1 \pm 1.0 \%$ respectively.

\subsection{Sensorial Analysis}

Fig. 6a-c shows the results of the sensorial analysis. The PLSR (Fig. 3) suggests that Softness and Cooking Degree were related to the cooking method. At $94^{\circ} \mathrm{C}$, Asterix and Bintje were softer for $\mathrm{CB}$ compared to SC. There was no significant difference between Cooking Degree for the different cooking methods.

Softness and Cooking Degree were negatively correlated to $92^{\circ} \mathrm{C}$ according to PLSR. Both Asterix and Bintje showed significant difference for Softness and Cooking Degree at $92^{\circ} \mathrm{C}$ compared to $94^{\circ} \mathrm{C}$ for $\mathrm{SC}$. Salome also showed a significant difference between $94^{\circ} \mathrm{C}$ and $96^{\circ} \mathrm{C}$ for $\mathrm{SC}$ and for Cooking degree also between $94^{\circ} \mathrm{C}$ and $96^{\circ} \mathrm{C}$ for $\mathrm{CB}$. 


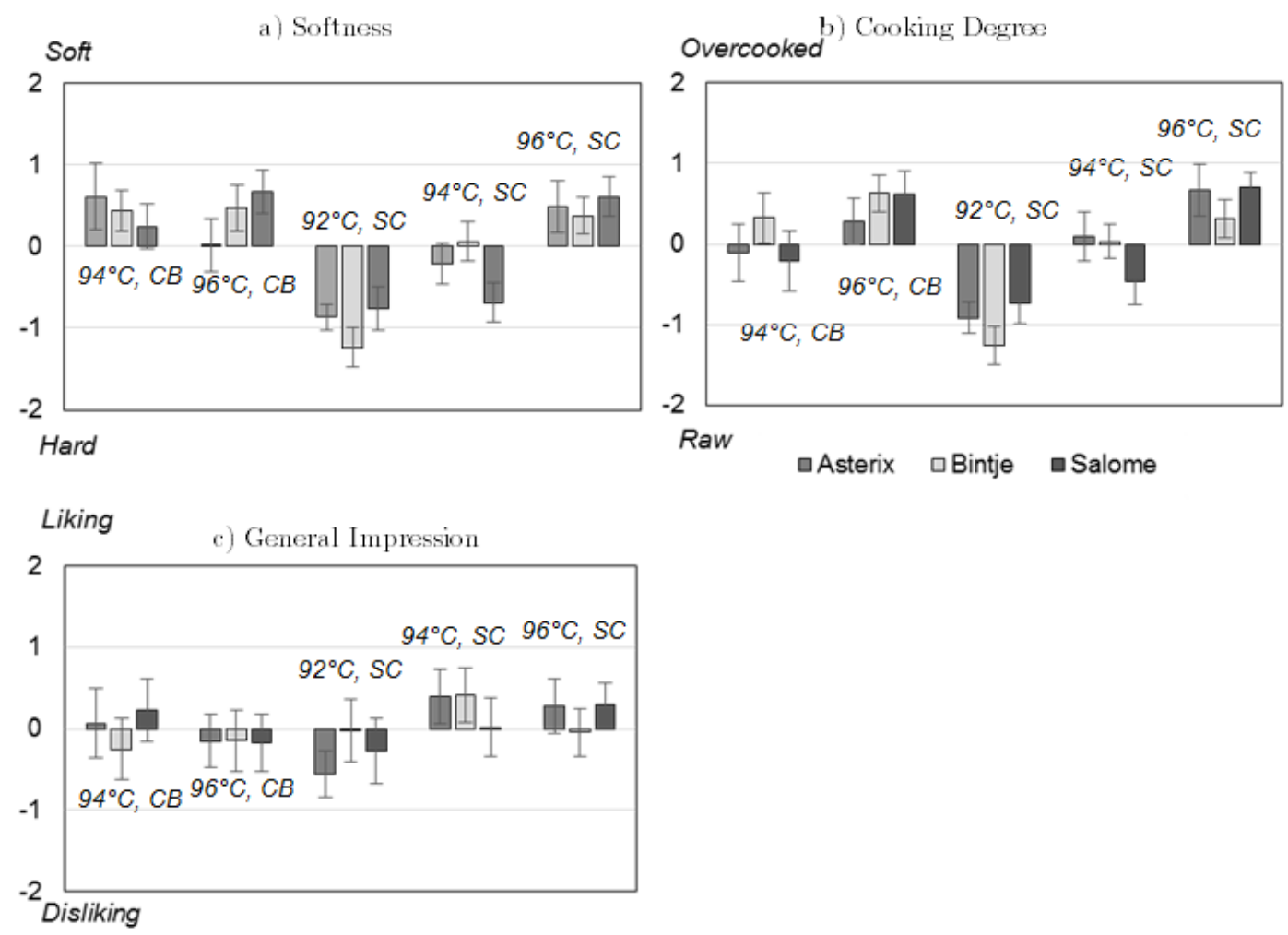

Figure 6. Normalized and standardized results from sensorial analysis for a) Softness, b) Cooking Degree and c) General Impression.

\subsection{Texture Analysis}

The peak force for each variety and cooking setup can be seen in Fig. 7.

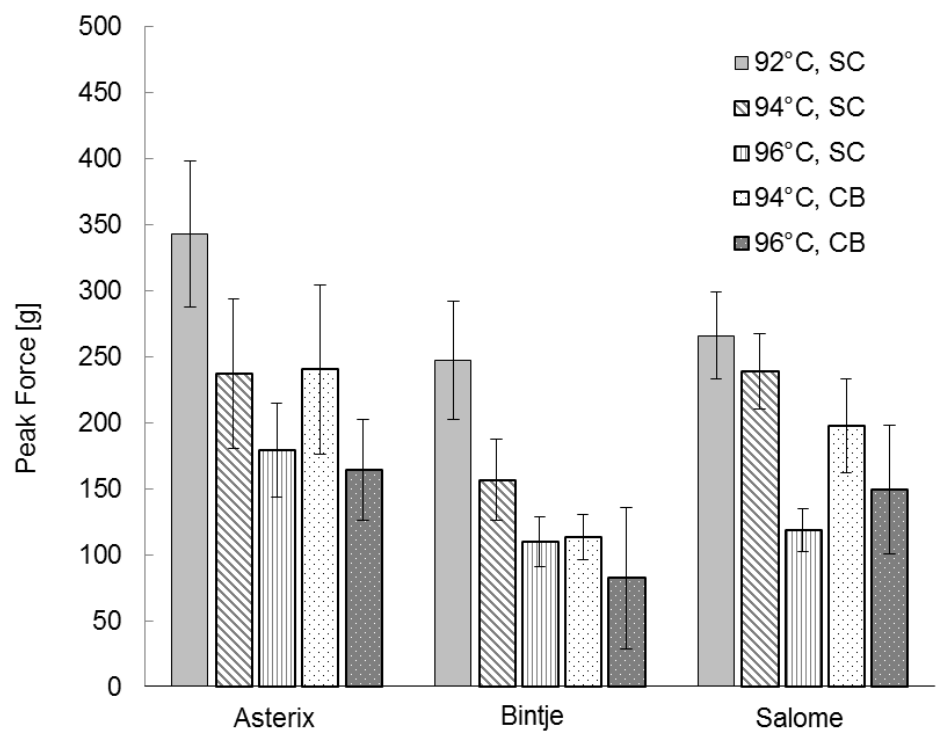

Figure 7. PF dependent on cooking setup. 
The general impression was not as well explained by the model as the other sensorial attributes, see Fig. 6c. The only significant difference was that Asterix, SC, $92^{\circ}$ was less popular than Asterix, SC, $94^{\circ} \mathrm{C}$ and $96^{\circ} \mathrm{C}$, Bintje, SC, $94^{\circ} \mathrm{C}$ and Salome, $\mathrm{SC}, 96^{\circ} \mathrm{C}$.

In general, there was a clear trend showing that higher temperature resulted in softer potatoes for both SC and CB. Bintje showed a significant difference between $\mathrm{SC}, 92^{\circ} \mathrm{C}$ and $\mathrm{SC}, 94^{\circ} \mathrm{C}$, and Salome showed significant difference between $\mathrm{SC}, 94^{\circ} \mathrm{C}$ and $\mathrm{SC}, 96^{\circ} \mathrm{C}$. Both of these agree well with the perceived Softness and Cooking Degree.

The mealy variety Bintje seems to soften the most between $92^{\circ} \mathrm{C}$ and $94^{\circ} \mathrm{C}$, resulting in a softer sample compared to the waxy varieties. This can be explained by previous findings, showing that lower temperature are required for mealy varieties to become cooked [24]. This phenomenon can also be observed in the PLSR (Fig. 3) where $\mathrm{PF}$ and $94^{\circ} \mathrm{C}$ is negatively correlated to Bintje, showing that Bintje becomes softer at $94^{\circ} \mathrm{C}$.

\section{Conclusions}

The peak force agreed well when looking at the results for both Cooking Degree and Softness. PLSR based on Factor 1 and Factor 2 showed a strong positive correlation between Cooking Degree and Softness, and Factor 3 showed a positive correlation between PF and Softness. This means that texture analysis can be applied in order to predict the Softness and Cooking Degree of potatoes. However, the method might need to take into account more aspects in order to be able to predict when the potato is optimally cooked.

The negative correlation between Cooking Degree and General Impression showed that the panelists prefer undercooked potatoes to overcooked potatoes.

The General Impression was the sensorial parameter that best described the optimal cooking degree of the potatoes. The results for this property differed the most (see Fig. 6c), which might be explained by individual preferences among the panelists. Based on the combination of Fig. 6b and the PLSR (Fig. 3), $94^{\circ} \mathrm{C}$ seems to be the most suitable temperature to achieve an optimal Cooking Degree. However, it might be hard to set a general recommendation based only on temperature when factors such as cooking method and variety seem to have a significant impact as well.

Acknowledgements. Financial support was obtained from VINNOVA, 3N, RATIONAL AG and Kävlinge municipality. The authors will thank Ia Rosenlid and the students at YTH education 2016 for assistance in the sensorial analysis.

\section{References}

1. M. Eidstedt, "Food consumption and nutritive values, data up to 2016," www.jordbruksverket.se, 2017.

2. C. Ochsenbein, T. Hoffmann, F. Escher, H. Kneubuehler, and A. Keiser, "Methods to routinely predict the texture quality of potatoes by tuber specific gravity," Journal of Texture Studies, vol. 41, no. 1, pp. 1-16, 2010.

3. B. Svensson, "Formation of a compact layer in pre-peeled potatoes," Swedish Journal of Agricultural Research, vol. 1, pp. 51-53, 1971.

4. M. Danowska-Oziewicz, M. Karpinska-Tymoszczyk, and J. Borowski, "The effect of cooking in a steamconvection oven on the quality of selected dishes," Journal of Foodservice, vol. 18, no. 5, pp. 187-197, 2007.

5. M. Andersson, E. Carlsson, and B. Nilsson Bergström, "Temperaturmätning och sensorisk bedömning vid kokning av potatis," 1990

6. M. E. Karlsson and A. C. Eliasson, "Effects of time/temperature treatments on potato (Solanumtuberosum) starch: a comparison of isolated starch and starch insitu," Journal of the Science of Food and Agriculture, vol. 83, no. 15, pp. 1587-1592, 2003.

7. M. Haydar, K. Moledina, B. Ooraikul, and D. Hadziyev, "Effect of calcium and magnesium on cell wall and starch of dehydrated potato granules," Journal of Agricultural and Food Chemistry, vol. 28, no. 2, pp. 383-391, 1980 .

8. M. C. Jarvis, E. Mackenzie, and H. J. Duncan, "The textural analysis of cooked potato. II. Swelling pressure of starch during gelatinisation," Potato Research, vol. 35, no. 2, pp. 93-102, 1992. 
9. C. Van Dijk, J. G. Beekhuizen, C. Boeriu, M. Fischer, and T. Stolle-Smits, "Texture of cooked potatoes (Solanum tuberosum). 3. Preheating and the consequences for the texture and cell wall chemistry," (in English), Journal of Agricultural and Food Chemistry, Article vol. 50, no. 18, pp. 5098-5106, 2002.

10. T. Imaizumi, F. Tanaka, D. Hamanaka, Y. Sato, and T. Uchino, "Effects of hot water treatment on electrical properties, cell membrane structure and texture of potato tubers," Journal of Food Engineering, Article vol. 162, pp. 56-62, 2015 .

11. L. G. Bartolome and J. E. Hoff, "Firming of potatoes; biochemical effects of preheating," Journal of Agricultural and Food Chemistry, vol. 20, no. 2, pp. 266-270, 1972.

12. G. E. Anthon and D. M. Barrett, "Kinetic parameters for the thermal inactivation of quality-related enzymes in carrots and potatoes," Journal of Agricultural and Food Chemistry, vol. 50, no. 14, pp. 4119-4125, 2002.

13. P. Garcia-Segovia, A. Andres-Bello, and J. Martinez-Monzo, "Textural properties of potatoes (Solanum tuberosum L., cv. Monalisa) as affected by different cooking processes," Journal of Food Engineering, vol. 88, no. 1, pp. 28-35, 2008.

14. L. Kaaber, T. Kriznik, E. Bråthen, S. H. Knutsen, and K. Kaack, "Structure of pectin in relation to abnormal hardness after cooking in pre-peeled, cool-stored potatoes," (in English), LWT - Food Science and Technology, Article vol. 40, no. 5, pp. 921-929, 2007.

15. G. M. Sapers, P. H. Cooke, R. L. Miller, A. E. Heidel, and S. T. Martin, "Structural changes related to texture of pre-peeled potatoes," (in English), Journal of Food Science, Article vol. 62, no. 4, pp. 797-803, 1997.

16. L. Alessandrini, S. Romani, P. Rocculi, I. Sjoeholm, and M. D. Rosa, "Effect of steam cooking on the residual enzymatic activity of potatoes cv. Agria," Journal of the Science of Food and Agriculture, vol. 91, no. 12, pp. 2140-2145, 2011.

17. S. Binner, W. G. Jardine, C. M. C. G. Renard, and M. C. Jarvis, "Cell wall modifications during cooking of potatoes and sweet potatoes," Journal of the Science of Food and Agriculture, vol. 80, no. 2, p. 216, 2000.

18. S. Schwimmer and H. K. Burr, "Structure and chemical composition of the potato tuber," in Potato processing, W. F. Talburt and O. Smith, Eds.: New York : Van Nostrand Reinhold, cop. 1987 4. ed., 1959, pp. 12-43.

19. H. J. Martens and A. K. Thybo, "An integrated microstructural, sensory and instrumental approach to describe potato texture," Lebensmittel-Wissenschaft und-Technologie, vol. 33, no. 7, pp. 471-482, 2000.

20. D. R. McComber, H. T. Horner, M. A. Chamberlin, and D. F. Cox, "Potato cultivar differences associated with mealiness," Journal of Agricultural and Food Chemistry, vol. 42, no. 11, pp. 2433-2439, 1994.

21. M. L. Weaver et al., "Potato composition: I. Tissue selection and its effects on solids content and amylose/amylopectin ratios," American Potato Journal, vol. 55, no. 2, pp. 73-82, 1977.

22. J. T. van Marle, A. C. M. Clerkx, and A. Boekestein, "Cryo-Scanning Electron Microscopy Investigation of the Texture of Cooked Potatoes," Food Structure, vol. 11, no. 3, pp. 209-216, 1992.

23. J. Singh, L. Kaur, O. J. McCarthy, P. J. Moughan, and H. Singh, "Rheological and textural characteristics of raw and par-cooked Taewa (Maori potatoes) of New Zealand," Journal of Texture Studies, vol. 39, no. 3, pp. 210-230, 2008.

24. A. Bordoloi, L. Kaur, and J. Singh, "Parenchyma cell microstructure and textural characteristics of raw and cooked potatoes," Food Chemistry, vol. 133, no. 4, pp. 1092-1100, 2012. 